\title{
A Seasonal Box-Jenkins Model for Nigerian Inflation Rate Series
}

\author{
Ette Harrison Etuk ${ }^{1}$, Atto Asuquo ${ }^{1} \&$ Isaac Didi Essi ${ }^{1}$ \\ ${ }^{1}$ Department of Mathematics/Computer Science, Rivers State University of Science and Technology, Nigeria \\ Correspondence: Ette Harrison Etuk, Department of Mathematics/Computer Science, Rivers State University of \\ Science and Technology, Nigeria. Tel: 234-813-694-8161. E-mail: ettetuk@yahoo.com
}

Received: January 28, 2012 Accepted: February 16, 2012 Online Published: July 20, 2012

doi:10.5539/jmr.v4n4p107 URL: http://dx.doi.org/10.5539/jmr.v4n4p107

\begin{abstract}
Time series analysis of Nigerian Inflation rate series is done. A seasonal difference and then a non-seasonal one were obtained. The correlogram of the differenced series revealed a seasonal nature. It also revealed a seasonal moving average component and a non-seasonal autoregressive component. $A(5,1,0) \times(0,1,1)_{12}$ seasonal model was fitted and shown to be adequate.
\end{abstract}

Keywords: inflation, ARIMA modelling, seasonal models, Nigeria

\section{Introduction}

A time series is defined as a set of data collected sequentially in time. It has the property that neighbouring values are correlated. This tendency is called autocorrelation. A time series is said to be stationary if it has a constant mean and variance. Moreover the autocorrelation is a function of the lag separating the correlated values and called the autocorrelation function (ACF).

A stationary time series $\left\{X_{t}\right\}$ is said to follow an autoregressive moving average model of orders $p$ and $q$ (designated $\operatorname{ARMA}(p, q)$ if it satisfies the following difference

$$
X_{t}+1 X_{t-1}+2 X_{t-2}+\ldots+p X_{t-p}=\varepsilon_{t}+\beta_{1} \varepsilon_{t-1}+\beta_{2} \varepsilon_{t-2}+\beta_{q} \varepsilon_{t-q}
$$

or

$$
A(L) X_{t}=B(L) \varepsilon_{t}
$$

where $\left\{\varepsilon_{t}\right\}$ is a sequence of uncorrelated random variables with zero mean and constant variance, called a white noise process, and the $\alpha_{i}^{\prime} s$ and $\beta_{j}^{\prime} s$ constants;

$$
A(L)=1+\alpha_{1} L+\alpha_{2} L^{2}+\ldots+\alpha_{p} L^{p}
$$

and

$$
B(L)=1+\beta_{1} L+\beta_{2} L^{2}+\ldots+\beta_{q} L^{q}
$$

and $L$ is the backward shift operator defined by $L^{k} X_{t}=X_{t-k}$.

If $p=0$, model (1) becomes a moving average model of order $q$ (designated MA(q)). If, however, $q=0$ it becomes an autoregressive process of order $p$ (designated AR(p)). An AR(p) model of order $p$ may be defined as a model whereby a current value of the time series $X_{t}$ depends on the immediate past $p$ values: $X_{t-1}, X_{t-2}, \ldots$, $X_{t-p}$. On the other hand an MA(q) model of order $q$ is such that the current value $X_{t}$ is a linear combination of the immediate past values of the white noise process: $\varepsilon_{t-1}, \varepsilon_{t-2}, \ldots, \varepsilon_{t-q}$. Apart from stationarity, invertibility is another important requirement for a time series. It refers to the property whereby the covariance structure of the series is unique (Priestley, 1981). Moreover it allows for meaningful association of current events with the past history of the series (Box \& Jenkins, 1976).

An AR(p) model may be more specifically written as

$$
X_{t}+\alpha_{p 1} X_{t-1}+\alpha_{p 2} X_{t-2}+\ldots+\alpha_{p q} X_{t-q}=\varepsilon_{t}
$$

Then the sequence of the last coefficients $\left\{\alpha_{i i}\right\}$ is called the partial autocorrelation function (PACF) of $\left\{X_{t}\right\}$. The ACF of an MA(q) cuts off after lag $q$ whereas that of an AR(p) model is a combination of sinusoidals dying off 
slowly. On the other hand the PACF of an MA(q) model dies off slowly whereas that of an AR(p) model cuts off after lag $p$. AR and MA models are known to have some duality properties. These include:

1) A finite order AR model is equivalent to an infinite order MA model.

2) A finite order MA model is equivalent to an infinite order AR model.

3) The ACF of an AR model exhibits the same behaviour as the PACF of an MA model.

4) The PACF of an AR model exhibits the same behaviour as the ACF of an MA model.

5) An AR model is always invertible but is stationary if $A(L)=0$ has roots outside the unit circle.

6) An MA model is always stationary but is invertible if $B(L)=0$ has roots outside the unit circle.

Parametric parsimony consideration in model building entails preference for the mixed ARMA fit to either the pure AR of the pure MA fit. Stationarity and invertibility conditions for model (1) or (2) are that the equations $A(L)=0$ and $B(L)=0$ should have roots outside the unit circle respectively.

Often in practice a time series is non-stationary. Box and Jenkins (1976) proposed that differencing of an appropriate order could render a non-stationary series $\left\{X_{t}\right\}$ stationary. Let the degree of differencing necessary for stationarity be d. Such a series $\left\{X_{t}\right\}$ may be modelled as

$$
\left(1+\alpha_{1} L+\alpha_{2} L^{2}+\ldots+\alpha_{p} L^{p}\right) \nabla^{d} X_{t}=B(L) \varepsilon_{t}
$$

where $\nabla=1-L$ and in which case

$$
A(L)=\left(1+\alpha_{1} L+\alpha_{2} L^{2}+\ldots+\alpha_{p} L^{p}\right) \nabla^{d}=0
$$

shall have unit roots $d$ times. Then differencing to degree $d$ renders the series stationary. The model (3) is said to be an autoregressive integrated moving average model of orders $p, d$ and $q$ and designated ARIMA(p,d,q).

\subsection{Seasonal ARIMA Models}

A time series is said to be seasonal of order $d$ if there exists a tendency for the series to exhibit periodic behaviour after every time interval $d$. Traditional time series methods involve the identification, unscrambling and estimation of the traditional components: secular trend, seasonal component, cyclical component and the irregular movement. For forecasting purpose, they are reintegrated. Such techniques could be quite misleading.

The time series $\left\{X_{t}\right\}$ is said to follow a multiplicative $(p, d, q) \times(P, D, Q)_{s}$ seasonal ARIMA model if

$$
A(L) \Phi\left(L^{s}\right) \nabla^{d} \nabla_{s} D X_{t}=B(L) \Theta\left(L^{s}\right) \varepsilon_{t}
$$

where $\Phi$ and $\Theta$ are polynomials of order $P$ and $Q$ respectively. That is,

$$
\begin{gathered}
\Phi\left(L^{s}\right)=1+\phi_{1} L^{s}+\ldots+\phi_{P} L^{s P} \\
\Theta\left(L^{s}\right)=1+\theta_{1} L+\ldots+\theta_{Q} L_{s} Q
\end{gathered}
$$

where the $\phi_{i}$ and $\theta_{j}$ are constants such that the roots of the equations (5) and (6) are all outside the unit circle for stationarity and invertibility respectively. Equation (5) represents the autoregressive operator whereas (6) represents the moving average operator.

Existence of a seasonal nature is often evident from the time plot. Moreover for a seasonal series the ACF or correlogram exhibits a spike at the seasonal lag. Box and Jenkins (1976) and Madsen (2008) are a few authors that have written extensively on such models. A knowledge of the theoretical properties of the models provides basis for their identification and estimation. The purpose of this paper is to fit a seasonal ARIMA model to Nigerian Inflation Rate Series (NINFR). Earlier works on Nigerian inflation include Abidemi and Maliq (2010), Olatunji et al. (2010) and Chiakwelu (2012). Whereas Abidemi and Maliq think that Nigerian inflation rates are stationary Olatunji et al. are of a contrary opinion. The graph of the inflation rates from 1990 to 2010 given by Chiakwelu corroborates the opinion of Olatunji et al. There is, perhaps, no known earlier attempt to model Nigerian inflation rates by a seasonal ARIMA model. 


\section{Materials and Methods}

The data for this work are monthly composite price index series (NCPI) from March 1963 to December 2003 obtainable from the Abstracts of the National Bureau of Statistics of Nigeria. The inflation rate was calculated by

$$
\operatorname{NINFR}(t)=[N C P T(t)-N C P I(t-1)] / N C P I(t-1)
$$

\subsection{Determination of the Orders $d, D, p, P, q$ and $Q$}

Seasonal differencing is necessary to remove the seasonal trend. If there is secular trend non-seasonal differencing will be necessary. To avoid undue complexity it has been advised that orders of differencing $\mathrm{d}$ and $\mathrm{D}$ should add up to at most 2 (i.e. $d+D<3$ ). If the ACF of the differenced series has a positive spike at the seasonal lag then a seasonal AR component is suggestive; if it has a negative spike then a seasonal MA term is suggestive. As already mentioned above, an AR(p) model has a PACF that truncates at lag p and an MA(q) has an ACF that truncates at $\operatorname{lag} q$. In practice $\pm 2 / \sqrt{n}$ where $n$ is the sample size are the non-significance limits for both functions.

\subsection{Model Estimation}

The involvement of the white noise terms in an ARIMA model entails a nonlinear iterative process in the estimation of the parameters. An optimization criterion like least error sun of squares, maximum likelihood or maximum entropy is used. An initial estimate is usually used. Each iteration is expected to be an improvement on the last one until the estimate converges to an optimal one. However, for pure AR and a pure MA models linear optimization techniques exist (See for example, Box \& Jenkins, 1976; Oyetunji, 1985). There are attempts to adopt linear methods to estimate ARMA models (See for example, Etuk, 1987; 1998). We shall use Eviews software which employs the least squares approach involving nonlinear iterative techniques.

\subsection{Diagnostic Checking}

The model that is fitted to the data should be tested for goodness-of-fit. We shall do some analysis of the residuals of the model. If the model is correct, the residuals would be uncorrelated and would follow a normal distribution with mean zero and constant variance. The autocorrelations of the residuals should not be significantly different from zero.

\section{Results and Discussion}

The time plot of the original series in Figure 1 does not show any secular trend. Because of the so many spikes involved seasonality is not obvious. Seasonal (i.e. 12-month) differencing of the series produces a series SDNINFR with no trend and no noticeable seasonality still. See Figure 2 for this time plot. Non-seasonal differencing yields a series DSDNINFR with no trend and no clear seasonality (see Figure 3). Its ACF in Figure 4 has a negative spike at lag 12 revealing a seasonality of lag 12 and a seasonal MA component to the model. The PACF cuts off at lag 5 suggesting the involvement of a non-seasonal AR(5) component. We therefore propose a $(5,1,0) \times(0,1,1)_{12}$ seasonal model. That means

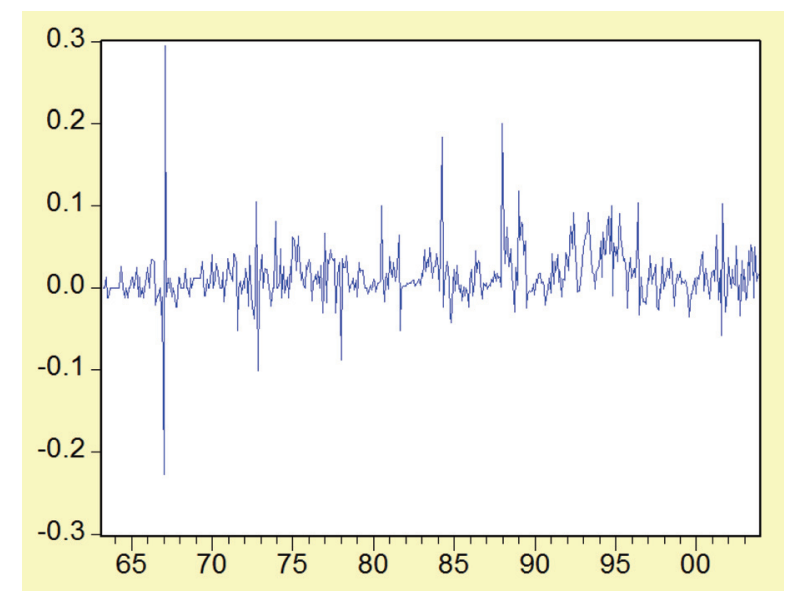

Figure 1. NINFR 


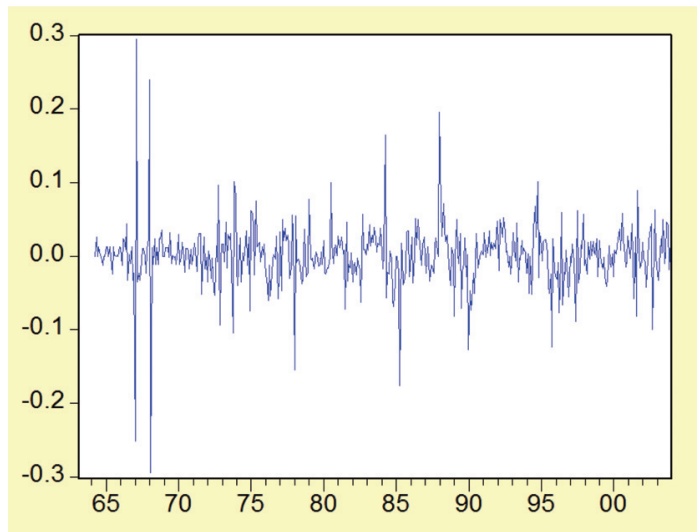

Figure 2. SDNINFR

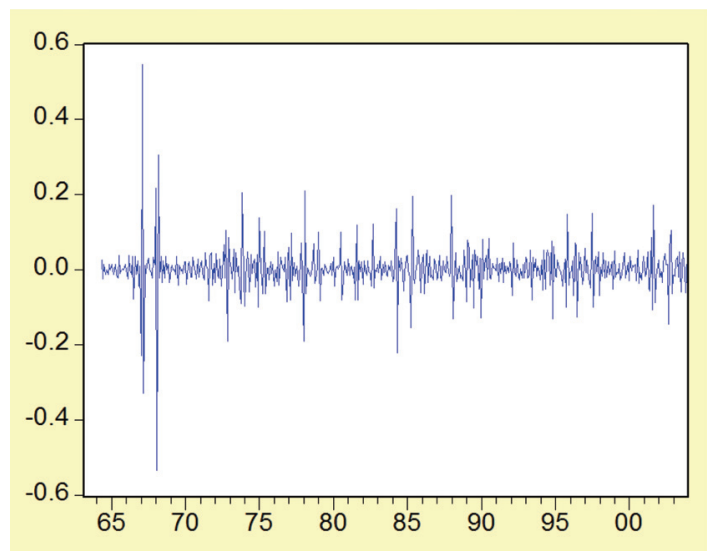

Figure 3. DSDNINFR

\begin{tabular}{|c|c|c|c|c|c|}
\hline Autocorrelation & Partial Correlation & $\mathrm{AC}$ & PAC & Q-Stat & Prob \\
\hline & $\square$ & $1-0.582$ & -0.582 & 161.99 & 0.000 \\
\hline 1) & $\square$ & 20.084 & -0.385 & 165.35 & 0.000 \\
\hline$\sqrt{1}$ & $\square$ & $3-0.046$ & -0.360 & 166.38 & 0.000 \\
\hline 1 & 당 & $\begin{array}{ll}4 & 0.081\end{array}$ & -0.234 & 169.57 & 0.000 \\
\hline$\sqrt{1}$ & 百 & $5-0.037$ & -0.171 & 170.22 & 0.000 \\
\hline ip & 11 & $\begin{array}{ll}6 & 0.047\end{array}$ & -0.034 & 171.26 & 0.000 \\
\hline f & & $\begin{aligned} 7 & -0.061\end{aligned}$ & -0.016 & 173.05 & 0.000 \\
\hline & & $8-0.007$ & -0.075 & 173.07 & 0.000 \\
\hline 小 & 4 & $\begin{array}{ll}9 & 0.019\end{array}$ & -0.103 & 173.25 & 0.000 \\
\hline$\sqrt{1}$ & ㄴ. & $10-0.038$ & -0.217 & 173.94 & 0.000 \\
\hline ص & שי & $\begin{array}{ll}11 & 0.286\end{array}$ & 0.344 & 214.03 & 0.000 \\
\hline & & $12-0.481$ & -0.077 & 327.29 & 0.000 \\
\hline ص & 与' & $\begin{array}{ll}13 & 0.257\end{array}$ & -0.167 & 359.76 & 0.000 \\
\hline 1 & & $14-0.006$ & -0.114 & 359.77 & 0.000 \\
\hline 小 & & $15 \quad 0.013$ & -0.115 & 359.85 & 0.000 \\
\hline d & & $16-0.071$ & -0.119 & 362.31 & 0.000 \\
\hline 1) & & $17 \quad 0.066$ & -0.066 & 364.45 & 0.000 \\
\hline 1 & & $18-0.063$ & -0.033 & 366.44 & 0.000 \\
\hline 1) & I & $\begin{array}{ll}19 & 0.079\end{array}$ & 0.033 & 369.51 & 0.000 \\
\hline$\sqrt{1}$ & & $20-0.041$ & 0.008 & 370.35 & 0.000 \\
\hline & & $21-0.004$ & -0.040 & 370.36 & 0.000 \\
\hline & & 220.000 & -0.125 & 370.36 & 0.000 \\
\hline W & 当 & $23 \quad 0.015$ & 0.229 & 370.47 & 0.000 \\
\hline 川 & . & $24-0.025$ & -0.057 & 370.79 & 0.000 \\
\hline 1) & & $\begin{array}{ll}25 & 0.030\end{array}$ & -0.122 & 371.24 & 0.000 \\
\hline t & & $26-0.031$ & -0.088 & 371.73 & 0.000 \\
\hline & & $27 \quad 0.004$ & -0.105 & 371.74 & 0.000 \\
\hline $1 / 1$ & d. & $\begin{array}{ll}28 & 0.031\end{array}$ & -0.085 & 372.23 & 0.000 \\
\hline 川 & 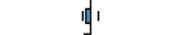 & $29-0.028$ & -0.051 & 372.65 & 0.000 \\
\hline 1 & d & $\begin{array}{ll}30 & 0.004\end{array}$ & -0.065 & 372.65 & 0.000 \\
\hline 7 & & $31-0.011$ & -0.032 & 372.71 & 0.000 \\
\hline$h_{1}$ & & $\begin{array}{ll}32 & 0.027\end{array}$ & -0.006 & 373.10 & 0.000 \\
\hline & & $33-0.003$ & -0.016 & 373.10 & 0.000 \\
\hline & d & $34-0.006$ & -0.067 & 373.12 & 0.000 \\
\hline 11 & שص? & $\begin{array}{ll}35 & 0.008\end{array}$ & 0.258 & 373.15 & 0.000 \\
\hline & yI & $36-0038$ & -0059 & 37391 & 0,000 \\
\hline
\end{tabular}

Figure 4. Correlogram of DSDNINFR 


$$
X_{t}+\alpha_{1} X_{t-1}+\alpha_{2} X_{t-2}+\alpha_{3} X_{t-3}+\alpha_{4} X_{t-4}+\alpha_{5} X_{t-5}=\beta_{12} \varepsilon_{t-12}+\varepsilon_{t}
$$

where $X$ represents DSDNINFR. The estimation of the model summarized in Table 1 yields the model

$$
\begin{gathered}
X_{t}+1.0162 X_{t-1}+0.8235 X_{t-2}+0.6157 X_{t-3}+0.3357 X_{t-4}+0.1435 X_{t-5}+0.9348 \varepsilon_{t-12}=\varepsilon_{t} \\
( \pm 0.0458)( \pm 0.0639)( \pm 0.0688)( \pm 0.0638)( \pm 0.0459)( \pm 0.0174)
\end{gathered}
$$

\begin{tabular}{|c|c|c|c|c|}
\hline $\operatorname{AR}(1)$ & -1.016220 & 0.045839 & -22.16910 & 0.0000 \\
\hline $\mathrm{AR}(2)$ & & & -12.8 & 0.0000 \\
\hline $\operatorname{AR}(3)$ & -0.615654 & 0.068778 & -8.9513 & 0.0000 \\
\hline $\operatorname{AR}(4)$ & -0.335682 & 0.063797 & -5.261719 & 0.0000 \\
\hline $\mathrm{AR}(5)$ & -0.143493 & 0.045897 & -3.126411 & 0.0019 \\
\hline MA(12) & -0.934773 & 0.017405 & -53.70707 & 0.0000 \\
\hline R-squared & 0.750042 & \multirow{6}{*}{\multicolumn{2}{|c|}{$\begin{array}{l}\text { Mean dependent var } \\
\text { S.D. dependent var } \\
\text { Akaike info criterion } \\
\text { Schwarz criterion } \\
\text { F-statistic } \\
\text { Prob(F-statistic) }\end{array}$}} & 4.47E-05 \\
\hline Adjusted R-sq & 0.747355 & & & 0.065535 \\
\hline S.E. of regressio & 0.032940 & & & -3.975574 \\
\hline Sum squared resid & 0.504559 & & & -3.922646 \\
\hline Log likelihood & 942.2478 & & & 279.0632 \\
\hline Durbin-Watson stat & 2.017964 & & & 0.000000 \\
\hline Inverted AR Roots & $\begin{array}{c}.21+.67 i \\
-.71\end{array}$ & $.21-.67 i$ & $-.36-.53 i$ & $-.36+.53 i$ \\
\hline Inverted MA Roots & $\begin{array}{c}.99 \\
.50-.86 \mathrm{i} \\
-.50-.86 \mathrm{i}\end{array}$ & $\begin{array}{r}.86+.50 i \\
.00+.99 i \\
-.86+.50 i\end{array}$ & $\begin{array}{r}.86-.50 \mathrm{i} \\
-.00-.99 \mathrm{i} \\
-.86-.50 \mathrm{i}\end{array}$ & $\begin{array}{c}.50+.86 i \\
-.50+.86 i \\
-.99\end{array}$ \\
\hline
\end{tabular}

Table 1. Model estimation dependent variable: DSDNINFR

The estimation involved 7 iterations. We note that all coefficients are significantly different from zero, each being larger than twice its standard error. The fact that $R^{2}=0.75$ implies that as much as $75 \%$ of the variations in DSDNINFR has been accounted for by the model. There is considerable agreement between the actual and the fitted models as shown in Figure 5. The histogram of the residuals in Figure 6 shows a normal distribution with zero mean. The correlogram of the residuals in Figure 7 further depicts the adequacy of the model since virtually all the autocorrelations are not significantly different from zero.

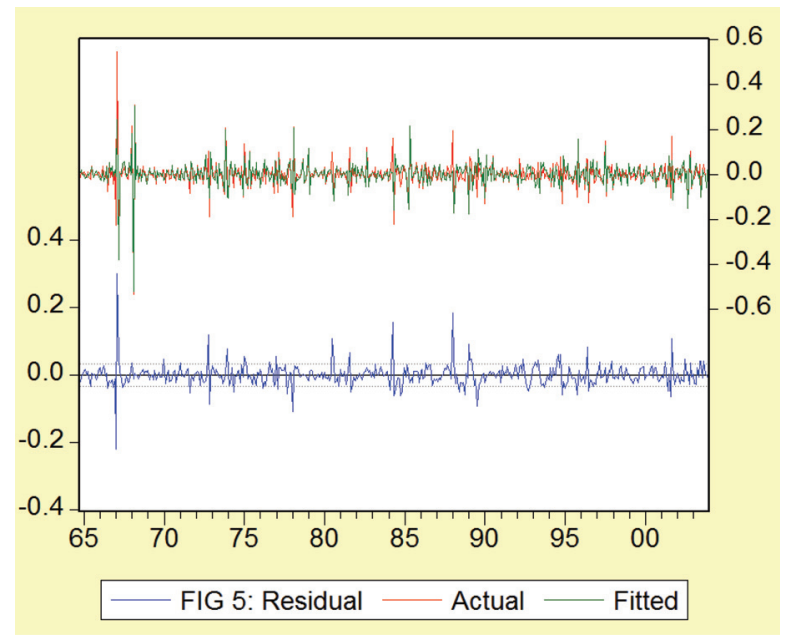

Figure 5. Residual 


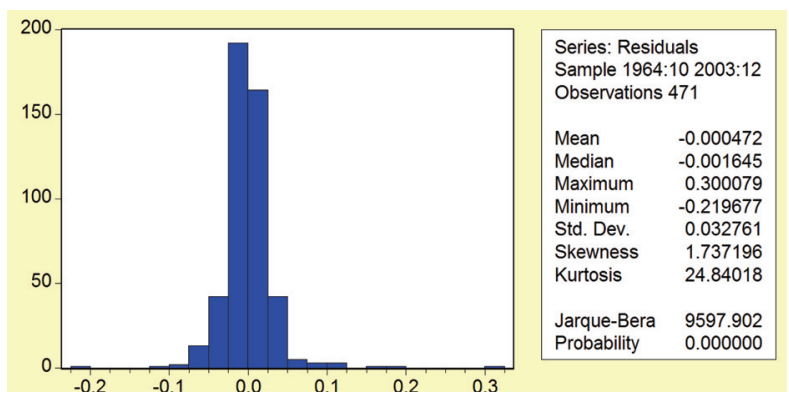

Figure 6. Histogram of the residuals

\begin{tabular}{|c|c|c|c|c|c|}
\hline Autocorrelation & Partial Correlation & $A C$ & PAC & Q-Stat & Prob \\
\hline 11 & 山 & $1-0.010$. & -0.010 & 0.0439 & \\
\hline i) & $1 / 1$ & $2-0.023$. & -0.023 & 0.2863 & \\
\hline id & 1. & $3-0.042$. & -0.043 & 1.1358 & \\
\hline d 1 & 1 & $4-0.068$. & & 3.3094 & \\
\hline 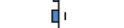 & i & $5-0.094$ & -0.098 & 7.5001 & \\
\hline 1 & 1 & $6-0.109$ & -0.120 & 13.212 & \\
\hline & '1 & $7-0.082$ & & 16.478 & 0.000 \\
\hline 1 & ' & $\begin{array}{ll}8 & -0.070 \\
9 & -0.023\end{array}$ & $\begin{array}{l}-0.102 \\
-0.067\end{array}$ & $\begin{array}{l}18.820 \\
19065\end{array}$ & $\begin{array}{l}0.000 \\
0.000\end{array}$ \\
\hline '|' & i & $10 \quad 0.023$ & $\begin{array}{l}-0.06 / \\
-0.029\end{array}$ & $\begin{array}{l}19.065 \\
19.327\end{array}$ & 0.001 \\
\hline 11 & 1 & 110.050 . & -0.004 & 20.532 & 0.001 \\
\hline ifi & il & 120.025 . & -0.026 & 20.846 & 0.002 \\
\hline i & 1 & 130.033 . & -0.012 & 21.377 & 0.003 \\
\hline if & iा & $14 \quad 0.049$ & 0.016 & 22.556 & 0.004 \\
\hline 11 & 1) 1 & $15-0.010$ & -0.029 & 22.606 & 0.007 \\
\hline iा & $\omega_{1}$ & $16-0.013$. & -0.020 & 22.691 & 0.012 \\
\hline iा & 1] & 170.006 & 0.009 & 22.709 & 0.019 \\
\hline 川 & 1 & $18-0.030$ & -0.021 & 23.156 & 0.026 \\
\hline 1 & iा & 190.004 & 0.015 & 23.165 & 0.040 \\
\hline 19 & 1 & $20-0.043$ & -0.037 & 24.093 & 0.045 \\
\hline i) & i & $21-0.023$. & -0.026 & 24.349 & 0.059 \\
\hline iा & 1) & $22-0.019$ & -0.028 & 24.531 & 0.079 \\
\hline iा & if & $23-0.012$. & -0.028 & 24.607 & 0.104 \\
\hline iा & 1 & $24-0.041$. & -0.066 & 25.430 & 0.114 \\
\hline if & ] & $25 \quad 0.025$. & -0.004 & 25.738 & 0.138 \\
\hline i & id & $26-0.007$. & -0.038 & 25.765 & 0.174 \\
\hline 1 & $1]$ & $27-0.002$ & -0.036 & 25.767 & 0.215 \\
\hline iti & i & $28 \quad 0.030$. & -0.005 & 26.235 & 0.242 \\
\hline 1 & 1 & $29-0.008$ & -0.038 & 26.264 & 0.289 \\
\hline iा & 4 & $30-0.020$ & -0.052 & 26.474 & 0.330 \\
\hline iा & 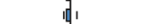 & $31-0.021$. & -0.049 & 26.688 & 0.372 \\
\hline i) & 1 & $32 \quad 0.010$ & -0.017 & 26.735 & 0.423 \\
\hline if & 小 & $33 \quad 0.031$ & 0.010 & 27.238 & 0.451 \\
\hline I & 1 & $34-0.002$ & -0.015 & 27.240 & 0.505 \\
\hline , & iा & $35-0.003$ & -0.019 & 27.246 & 0.558 \\
\hline 141 & 10 & $36-0.031$ & -0.053 & 27.730 & 0.585 \\
\hline
\end{tabular}

Figure 7. Correlogram of the residuals

\section{Conclusion}

The NINFR series has been shown to be nonstationary and to follow a $(5,1,0) \times(0,1,1)_{12}$ model. This model has been shown to be highly adequate.

\section{References}

Abidemi, O. I., \& Maliq, A. A. A. (2010). Analysis of Inflation and its determinants in Nigeria. Pakistan Journal of Social Sciences, 7(2), pp. 97-100. http://dx.doi.org/10.3923/pjssci.2010.97.100

Box, G. E. P., \& Jenkins, G. M. (1976). Time Series Analysis, Forecasting and Control. Holden-Day, San Francisco.

Chiakwelu, E. (2012). Nigeria: Inflation spikes, Naira recoils and T-bills sell continues. Africa Political and Economic Strategic Center, AFRIPOL. http://www.Afripol.org

Etuk, E. H. (1987). On the Selection of Autoregrressive Moving Average Models. An unpublished Ph. D. Thesis, Department of Statistics, University of Ibadan, Nigeria.

Etuk, E. H. (1998). An Autoregressive Integrated Moving Average (ARIMA) Model: A Case Study. Discovery and Innovation, $10(1 \& 2)$, pp. 23-26.

Madsen, H. (2008). Time Series Analysis. London: Chapman \& Hall/CRC.

Olatunji, G. B., Omotesho, O. A., Ayinde, O. E., \& Ayinde, K. (2010). Determinants of inflation in Nigeria: A co-integration approach. Contributed paper presented at the Joint 3rd African Association of Agriculture Economists(AAAE) and 48th Agricultural Economists Association of South Africa (AEASA) Conference, 
Cape Town, South Africa, September $19 \quad-\quad 23,2010 . \quad$ Retrieved from http://ageconsearch.umn.edu/bitstream/96162/2/103

Oyetunji, O. B. (1985). Inverse Autocorrelations and Moving Average Time Series modelling. Journal of Official Statistics, 1, 315-322.

Priestley, M. B. (1981). Spectral Analysis and Time Series. London: Academic Press. 